\title{
science \\ The 2021 Korean National Open Access Policy Forum
}

\author{
So-Hyeong Kim \\ National Research Foundation of Korea, Daejeon, Korea
}

\section{Brief meeting information}

Date and delivery method: June 17, 20212 p.m. to 5 p.m., live broadcast on Naver TV, Kakao $\mathrm{TV}$, and YouTube.

Venue: GLAD Yeouido Hotel, Seoul, Korea.

Organized by: Offices of Members of the National Assembly of the Republic of Korea including Wonwook Lee, Dukgoo Kang, and Yeungshik Kim.

Hosted by: National Research Foundation of Korea, Korea Federation of Science and Technology Societies, and Korea Institute of Science and Technology Information.

Sponsored by: Ministry of Education and Ministry of Science and Technology Information and Communication.

Purpose: The purpose of the 2021 National Open Access Policy of Korea was to design comprehensive measures for the direction of a national open access (OA) policy in South Korea, with goals such as providing free access to government-funded research results, encouraging OA publication in domestic academic journals, and mitigating expensive international journal subscription fees.

\section{Introduction}

The 2021 Korean National Open Access Policy Forum was held on June 17, 2021, in Seoul, Korea (Fig. 1). This paper aimed to summarize the proceedings to advance the discussion of OA policies among scholarly journal editors and researchers in Korea. The content of this paper may be helpful for editors who manage journals and for researchers selecting journals for future submissions. In this paper, the presentations by the three speakers are described, followed by a summary of the discussion between the six panelists and comments by the chair of the panel discussion. Finally, potential future directions regarding OA policy in Korea are sug-

Received: July 24, 2021

Accepted: August 3, 2021

Correspondence to So-Hyeong Kim mini@nrf.re.kr

ORCID

So-Hyeong Kim

https://orcid.org/0000-0002-3973-6782 gested.

\section{Presentation Topics of the Three Speakers}

Challenges and tasks for OA (Jeong-Wook Seo, Director of Clinical Research Center, Incheon Sejong Hospital, Incheon and Professor Emeritus, Seoul National University) The OA movement commenced in earnest in the late 1990s and the early 2000s. Researchers 


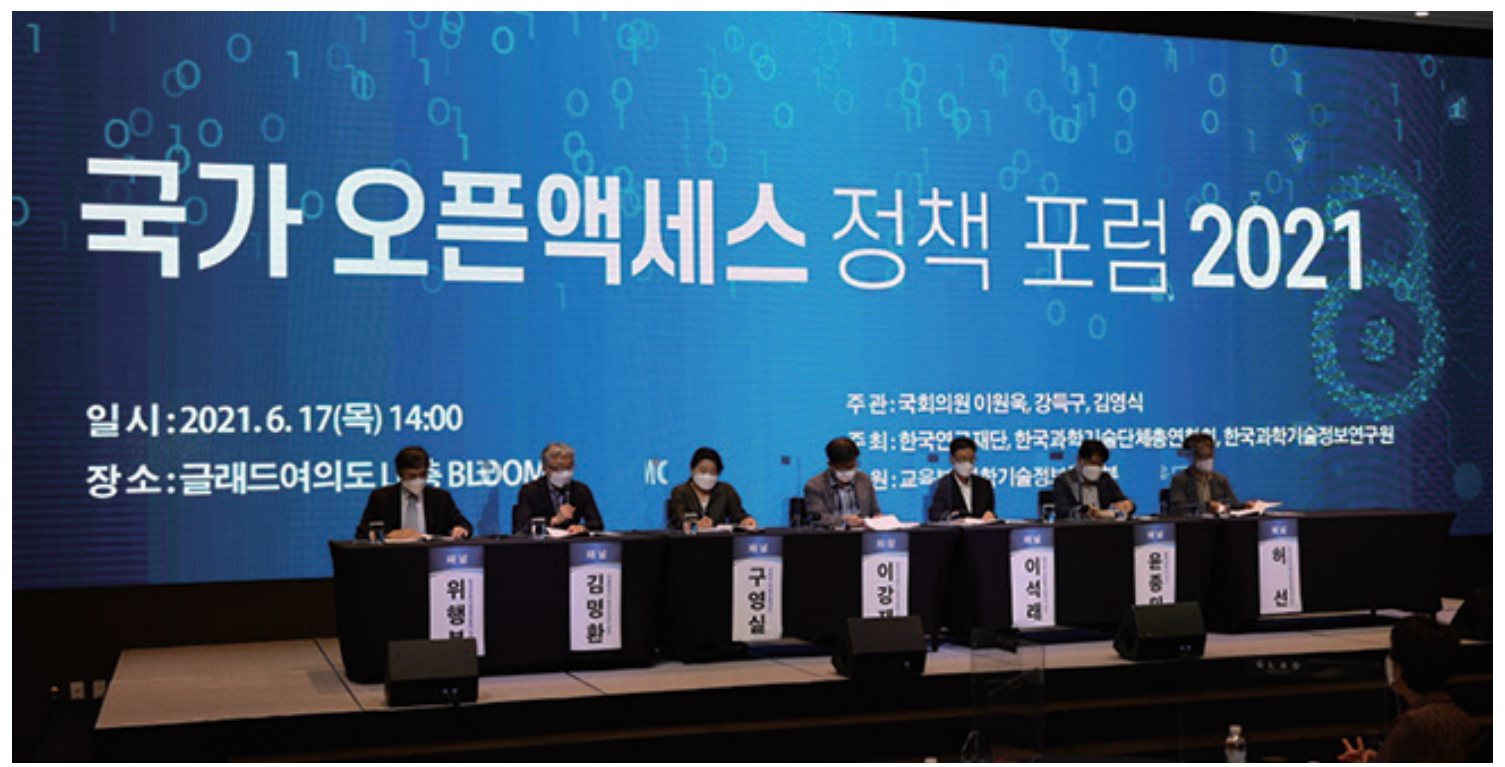

Fig. 1. Photo of six panelists and the chair at the 2021 Korean National Open Access Policy Forum, held on June 17, 2021, in Seoul, Korea.

tend to prefer OA since it ensures that their papers will be read and cited more; however, publishers prefer there to be an article processing charge (APC). As a result, researchers are often required to pay a fee to publishers when publishing $\mathrm{OA}$ articles to ensure profitability.

When Seoul National University (SNU) professors first began to publish OA articles, the university supported APCs, and the APCs borne by the university gradually increased. Later, SNU imposed an upper limit of APCs per professor. SNU and its professors paid an estimated 3.4 billion Korean won to publishers in 2015. In addition, the costs associated with subscribing to international journals at SNU libraries increased tenfold from 860 million Korean won in 2002 to 8.96 billion Korean won in 2015. Subscription fees for university libraries in Korea have been growing by $3 \%$ to $4 \%$ every year. Although the cost increase related to APCs was higher, journal subscription costs also increased.

This phenomenon is not just a Korean issue, but also a global one. These issues led to the implementation of Plan S in Europe. The "S" in "Plan S" stands for "shock," and the policy was in turn designed to mitigate the problem by giving it a "shock," mandating that all papers funded using public research funds from all countries in the European Union must be published as OA articles beginning in January 2021. Foreign libraries struggle with the same issues as Korean libraries. Since this is a global issue, it is necessary to collaborate with stakeholders regarding the legal and institutional mechanisms that can be used to implement OA policies and lay the groundwork for OA policy in the future.
Subscription journal issues and the transition to OA (Hwan-Min Kim, Secretary-General of Korean E-resource Service for Library, Korea Institute of Science and Technology Information)

Upon analyzing the publication volume of Science Citation Index Expanded papers by publisher, it was found that $78 \%$ of Science Citation Index Expanded papers by Korean authors were published by the top 20 publishers. In Korea, subscription-based publishers that do not specialize in OA are subject to major OA conversion contracts. The top 30 institutions in Korea produce about $70 \%$ of articles in subscription-based journals, and if a journal actively publishes OA papers, there will be quicker results. OA conversion contracts mainly comprise read-and-publish (RAP) agreements. Read-and-publish refers to an agreement that bundles access and publication costs together. Alternatively, publish-and-read agreements pay only for publishing and include access rights at no additional charge. Examining OA conversion contracts by publisher, Elsevier was found to have signed a publish-and-read contract with the University of California in March 2021 [1]. A contract between Wiley and Germany allowed OA publications for a fee of 2,750 euro per article [2]. After comparing the costs to publish OA articles in Wiley journals between Korea and Germany, Korea was found to pay a fee of 4,742 US dollars for the production of one article, while researchers from Germany can publish an OA article for a fee of 3,300 US dollars (2,750 euro) per article. When comparing the cost of publishing in Elsevier between Korea and the University of California, the estimated fee for producing one OA paper in Elsevier from Korea was 3,188 US dollars, while it was only 


\section{science editing /}

2,448 US dollars for the University of California. It was estimated that Korea currently spends approximately 180 billion Korean won annually on subscription fees and about 50 billion Korean won on APCs, adding up to an annual total of 230 billion Korean won.

Measures to support OA in domestic academic journals (Sook-Ja Park, President of the Society of Popular Narratives and Professor at Sogang University)

In a recent study, 32 leaders from humanities and social science journals participated in focus group interviews from December 2020 to June 2021 about journal support. Among the 32 respondents, $87 \%$ answered that "strengthening publicity (OA publishing)" is essential for journal support. However, respondents were also worried about OA conversion since it would result in no immediate income, such as copyright fees. In addition, they were concerned about whether public databases would become influential enough to replace commercial databases. Respondents still wanted the support of professional publishing companies, including services such as manuscript editing. The National Research Foundation of Korea supports only about $10 \%$ of the total 1,800 journals in the humanities and social sciences. Therefore, in order to strengthen the public reach of academic papers, the National Research Foundation of Korea has asked for financial support from the government to assist with OA conversion.

\section{Discussion by Six Panelists}

\section{Myung-Hwan Kim (General Director, SNU Library and} Professor at SNU)

The number of Korea Citation Index-registered journals in the humanities and social sciences is about 1,800 . Therefore, it is estimated that OA conversion can be attempted with an annual budget of 20 billion Korean won. In addition, it will be possible to quickly switch to OA using the National Research Foundation of Korea's journal evaluation system.

\section{Young-sil Koo (Director of Academic Research Affairs Division, Ministry of Education, Republic of Korea)} The Ministry of Education has supported removing barriers for accessing e-journals. Beginning in 2021, researchers at non-subscribing universities are now able to access e-journals at no cost. More budgets for similar initiatives are needed in the future.

Hang-bok Wee (President of the Korean Federation of Humanities and Social Sciences and emeritus professor at Hanyang University)

Many language barriers can be resolved using artificial intelli- gence. The corpus of academic papers in non-indigenous languages has significantly grown. In addition, institutions should refrain from giving professors more credit for publishing articles in international journals during the performance evaluation process.

\section{Chongmin Yoon (Professor at Graduate School of Law, Chungbuk National University)}

The question arises of how we can provide a legal basis for OA policy. A legal foundation for promoting OA based on related policies, including the Framework Act on Science and Technology [3] or the Science Promotion Act [4], must be established. In the National R\&D Innovation Act [5], regulations on how to specifically support diffusion in the disclosure, registration, and utilization of various research results, such as research reports and papers, should supplement a new policy. However, in order to make OA mandatory, it is necessary to distinguish between policy promotion and strengthening stakeholders' copyright. Implementation of policies such as financial support or budget support can be resolved by strengthening the relevant laws. Still, such policies could limit the rights of academic researchers. For example, mandatory OA may interfere with the rights of individual researchers concerning commercial publishers. Due to potential conflictof-interest issues related to mandatory OA policies, a cautious approach is required.

Seok-rae Lee (Officer of the Performance Evaluation Policy Bureau, Ministry of Science and ICT, Republic of Korea)

With enough financial support supplementing the publication costs of domestic academic journals, it will be possible to convert them to OA journals quickly. The Ministry of Science and ICT (Information and Communications Technology) currently provides scientific journals with approximately 2.1 billion Korean won annually, but it will gradually increase the amount to about 10 billion Korean won through the Korean Federation of Science and Technology Societies. Adding mandatory OA policies should be considered in the imminent future in light of the Framework Act on Science and Technology.

Sun Huh (Professor at College of Medicine, Hallym University)

To optimize the quality of academic OA journal promotion, $0.1 \%$ of the total R\&D budget of the Korean government should be designated for journal publishing support. As of 2021, 6.7 billion Korean won-about $0.025 \%$ of the total national R\&D budget-goes toward supporting academic journals. With an increase to $0.1 \%$ of the national R\&D budget, 
there would be a budget of approximately 27 billion Korean won. Researchers generally do not object to mandatory OA publication of government-funded research results, but one premise is crucial-namely, it is less burdensome to researchersif APCs can be paid using any research funds Usually, articles are published after the research is completed.

\section{Comment by the Chair of the Panel Discussion}

Kang-jae Lee, (Director of Humanities and Social Sciences Division, National Research Foundation of Korea, Professor of Chinese Language and Literature at SNU)

Although there are clear differences between the humanities and social science fields and science fields in a variety of aspects, everyone tends to agree that OA should be actively promoted. It is important to note that this forum was held openly in the interests of the National Assembly and the government. With the interest and active support of the Ministry of Education and Ministry of Science and ICT, the process of implementing new mandatory OA policies must be pursued.

\section{Conclusion}

This meeting was organized by three members of the National Assembly of the Republic of Korea. This indicates that representatives of the Korean people have a significant interest in OA policy. In the United States, a public access policy was introduced by the United States National Institute of Health and the National Science Foundation [6]. In Europe, Plan S has been in place since January 2021, which requires mandatory OA publication for research results supported by specific funding organizations [7]. In Korea, the debate on OA policy has continued since the early 2000s. However, there was not always concrete legal support for an OA policy. The implementation of an OA policy pertaining to research articles supported by the Korean government should be differentiated from policies related to subscription journals published by commercial publishing companies. The most urgent immediate step is to establish a legal basis for the mandatory deposition of government-funded articles in public repositories or journal homepages immediately after publication. The second step is to discuss how to support author-side APCs related to OA publication. The third step is to help domestic society journals adopt OA policies when societies are unable to allocate sufficient budgetary resources for journals that do not have subscription fees. As for support for society journals, government officials have stated that more funding would be provided soon. Dr. Huh's proposal to dedicate $0.1 \%$ of the government's annual $\mathrm{R} \& \mathrm{D}$ budget to journal publishing may be the best incentive for journal editors. APCs may be a fi- nancial burden to researchers who wish to publish in top-tier international journals. The solution is either to allow a 1-year embargo period, as in the public access policy implemented in the United States, or to pay authors' APCs using research funds. Another way is to encourage researchers' institutions or other public funding agencies to assist with APCs, although such organizations cannot be forced to do so.

Since Korea is one of the top countries in the performance of science research, the adoption of an OA policy by the Korean government will be another milestone in the research literature market. I anticipate that this meeting will trigger the implementation of an OA policy in Korea.

\section{Conflict of Interest}

No potential conflict of interest relevant to this article was reported.

\section{Funding}

The author received no financial support for this article.

\section{References}

1. Hunt A, Davis A. University of California and Elsevier sign ground-breaking transformative agreement [Internet]. Amsterdam: Elsevier Press; 2021 [cited 2021 Jul 19]. Available from: https://www.elsevier.com/about/press-releases/corporate/university-of-california-and-elseviersign-ground-breaking-transformative-agreement

2. Kupferschmidt K. Deal reveals what scientists in Germany are paying for open access [Internet]. Washington, DC: Science Scientific Community; 2019 [cited 2021 Jul 19]. https:// doi.org/10.1126/science.aax1064

3. Framework Act on Science and Technology. Act No. 17347 [Internet]. Sejong: Korea Legislation Research Instiute; 2020 [cited $2021 \mathrm{Jul}$ 19]. Available from: https://elaw.klri.re.kr/ kor_service/lawView.do?hseq=54701\&lang=ENG

4. Sciences Promotion Act. Act No. 14163 [Internet]. Sejong: Korea Legislation Research Institute; 2016 [cited 2021 Jul 19]. Available from: https://elaw.klri.re.kr/kor_service/ lawView.do?hseq=38880\&lang=ENG

5. National Research and Development Act. Act No. 17343 [Internet]. Sejong: Kore Law Information Center; 2020 [cited 2021 Jul 19]. Available from: https://www.law.go.kr/ LSW/lsInfoP.do?efYd=20210101\&lsiSeq $=218729 \# 0000$

6. National Science Foundation. NSF 16-009. Public access: frequently asked questions [Internet]. Alexandria, VA: National Science Foundation [cited 2021 Jul 19]. Available from: https://www.nsf.gov/pubs/2016/nsf16009/nsf16009.jsp 
7. European Science Foundation. Plan S: making full and immediate open access a reality [Internet]. Strasbourg: Euro- pean Science Foundation; 2021 [cited 2021 Jul 19]. Available from: https://www.coalition-s.org/ 